\title{
A rare case of Mayer-Rokitansky-Kuster- Hauser syndrome with right ectopic kidney diagnosed on MRI
}

\author{
Rohan Kumar Singh, Prerna Anup Patwa* (1), Gaurav Vedprakash Mishra, Rajasbala Pradeep Dhande, \\ Suresh Vasant Phatak and K. B. Harshith Gowda
}

\begin{abstract}
Introduction: Meyer-Rokitansky-Küster-Hauser syndrome is rare congenital abnormality in females with a blind ending vagina. There can be associated hypoplasia of uterus. The syndrome is of sporadic origin and affects the reproductive life. Adequate and early diagnosis can help to rule out other associated anomalies.

Case presentation: We are presenting an interesting case of Mullerian agenesis in a 16-year-old female patient who came to our gynecology department of our hospital with complains of primary amenorrhea. On imaging, it was found that she was a case of Mayer-Rokitansky-Küster-Hauser syndrome with ectopic kidney. On physical examination, affected individuals appears normal but there was agenesis of uterus which is the common cause of primary amenorrhea. Magnetic resonance imaging findings are discussed in this article. On karyotyping and hormonal evaluation, patient hormones were in range and karyotype was 46, XX.

Conclusion: MRI is mainstay for diagnosis of this condition although other modalities like ultrasound can diagnose hypoplastic uterus and ectopic kidney. A rudimentary uterus hampers the reproductive functioning and patient needs counselling for the same.
\end{abstract}

Keywords: Mayer-Rokitansky-Kuster-Hauser syndrome, Mullerian agenesis, Primary amenorrhea, Ectopic kidney

\section{Introduction}

In about 1 in 5000 females affected by Mullerian duct anomalies, there is presence of primary amenorrhea and absent uterus resulting in blind ending tubular vagina [1]. So, condition where there is blind ending vagina, absent uterus and primary amenorrhea is known as Meyer-Rokitansky-Küster-Hauser syndrome. This syndrome is most common cause of primary amenorrhea in pubertal females [2]. Females having this condition are not able to have normal reproductive life and they usually go for assisted techniques for reproduction like in vitro fertilization etc. It is necessary for gynecologist to

*Correspondence: drprernapatwa@gmail.com

Department of Radiodiagnosis, Jawaharlal Nehru Medical College,

Sawangi (Meghe), Wardha, Maharashtra 442001, India council and explain the condition to the patient because after knowing that she is missing some organs it will put deep impact on her. If there is no menarche by the age of 13 years in association with absence of secondary sexual characteristics or menarche not achieved by 15 years of age with presence of secondary sexual characteristics, it is known as primary amenorrhea. Polycystic ovarian syndrome which is most common cause of secondary amenorrhea, can also present as primary amenorrhea. Pituitary and hypothalamic abnormalities, outflow disorders can be causes of primary amenorrhea [3]. Here in this article, we are presenting an interesting case of Mullerian agenesis in a 16-year-old female patient who came to our hospital with a complaint of primary amenorrhea. On the basis of clinical examination, magnetic resonance imaging and by correlation with the history given by 
the patient it was found that she was a case of MayerRokitansky-Küster-Hauser Syndrome with right sided ectopic kidney.

\section{Case presentation}

A 16-year-old young female patient visited to gynecology department of our hospital with chief complaint of primary amenorrhea. On careful history-taking from the mother and by patient herself, it was known that the patient had no history of periodic lower abdominal pain or urinary symptoms. There was no positive family history or same history in siblings. Secondary sexual characteristics were fully developed at about 14 years of age; the sequence of development could not be recalled. Breast development was normal and axillary and pubic hairs were present. She had normal axillary and pubic hair distribution. The genital examination revealed normal clitoris, labia major and minor. The gynecological examination revealed grossly normal vulva; however, the vagina was blind-ending with only the urethral opening being patent. The transabdominal ultrasonography performed did not reveal a uterus, although a blind ending vagina was seen on speculum examination. Both the ovaries were normal with multiple follicles within. Urinary tract anomalies were seen in form of right sided ectopic kidney. On magnetic resonance imaging no uterus was seen but bilateral ovaries were present (Figs. 1, 2). Additional finding of ectopic pelvic kidney was also noted on the pelvic MRI scan (Fig. 1). On karyotyping results were normal and other hormonal and laboratory test were within normal range. A diagnosis of Mayer-Rokitansky-Küster-Hauser Syndrome with right sided ectopic kidney. The diagnosis is confirmed mainly with imaging modalities of ultrasonography and magnetic resonance imaging. This helps to definitively characterize the anatomy. The preferred ultrasonography is the three-dimensional mode. Laparoscopy is considered when the earlier mentioned modalities have not yielded adequate information or in the treatment of rudimentary uterine horns. Karyotyping is also needed in establishing the diagnosis of Mayer-Rokitansky-Küster-Hauser Syndrome as it helps in differentiating it from the other clinical conditions that appear similar in appearances such as androgen insensitivity syndrome and $17 \alpha$-hydroxylase syndrome. All the findings were explained to the patient and proper counseling of the patient was done. Patient was advised for further follow up.

\section{Discussion}

Physiologist Mayer (1829), Rokitansky (1938), Küster (1910), and gynecologist Hauser (1961) described in 1829 [1]. Most common cause of primary amenorrhea in females is gonadal dysgenesis and second most common cause is Mayer-Rokitansky-Küster-Hauser Syndrome. This syndrome has incidence of 1 per 4000-10,000 females. This syndrome occurs due to interruption of developing Mullerian ducts during fourth to twelfth week of gestation. During normal development of bilateral Mullerian ducts these ducts fuse distally and forms lower two-thirds of the vagina and uterus and the proximal portion of the Mullerian ducts remain free and form the bilateral fallopian tubes. Generally, ovarian development is seen in this syndrome as ovaries do not develop from Mullerian ducts. Active endometrial tissue is seen in only

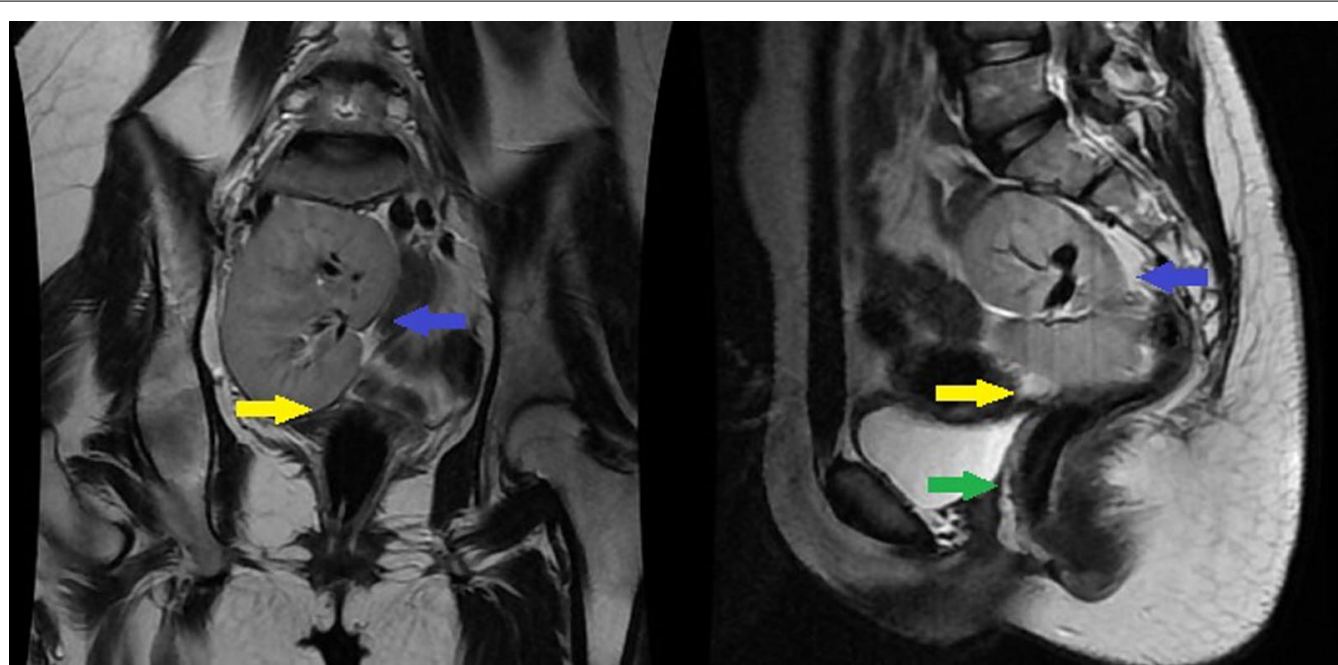

Fig. 1 MRI Coronal and Sagittal T2WI images showing no uterus (yellow arrow) in the pelvis, a long rudimentary vagina (green arrow) and right ectopic pelvic kidney (blue arrow) 


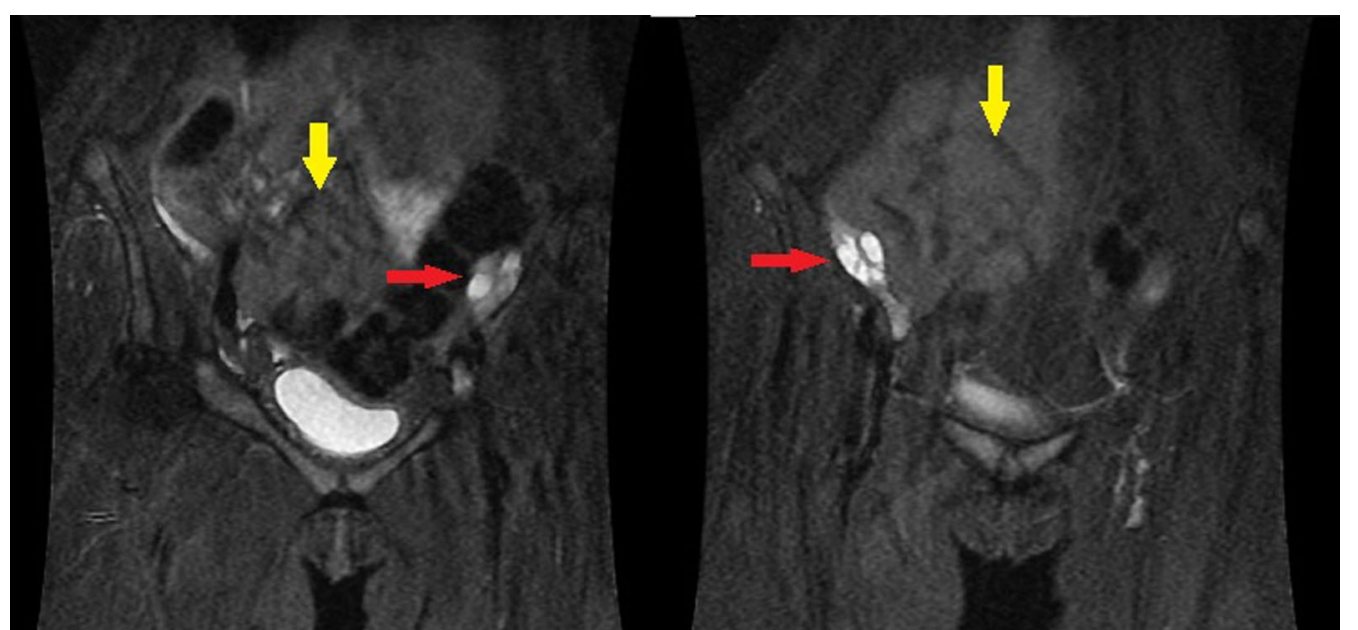

Fig. 2 MRI Coronal STIR images showing bilateral ovaries with multiple follicles (red arrow) and no evidence of uterus (yellow arrow)

$2 \%$ to $7 \%$ of patients with Mayer-Rokitansky-KüsterHauser Syndrome. Multiple genes are involved leading to this rare syndrome [4].

Typical presentation of Mayer-Rokitansky-KüsterHauser Syndrome is primary amenorrhea. Some may present with cyclical abdominal pain and gynecological examination may reveal absent or rudimentary vagina [5]. This syndrome occurs due to growth failure during embryogenesis resulting in agenesis or partial development of vagina or uterus or both [6]. The ovaries are of a different embryologic origin and they are normal in structure and function thus patients with this syndrome usually appear normal on physical examination with normal height and secondary sexual characteristics. The labia majora, labia minora, clitoris, hymen and distal portion of the vagina are usually present because this portion is of a different embryonic origin. The karyotype and hormone profile are also normal as seen in this case [7]. There are two subtypes of Mayer-RokitanskyKüster-Hauser syndrome: the typical and the atypical forms. Remnants of Mullerian ducts and bilateral normal fallopian tubes are seen on laparoscopy in typical form and atypical form shows dysplasia of fallopian tubes with hypoplasia of one or both buds with other associated anomalies like unilateral or bilateral renal agenesis, ectopic kidneys or horseshoe kidneys in $40-60 \%$ of cases. Other abnormalities include cervicothoracic, hearing defects and varying degrees of digital anomalies. The most severe form of the atypical form is referred to as Mullerian renal cervical somite association [8-11].

One should undergo clinical examination and imaging when there is no pubertal development by the age of 13 years or if menarche has not been achieved by the age of 15 years. When the patient does not achieved menarche within five years of thelarche, one should undergo imaging modalities for knowing the causes of primary amenorrhea. There are various reasons for primary amenorrhea that includes all the causes leading to secondary amenorrhea which includes normal pregnancy, increased prolactin levels in blood, pituitary and hypothalamus abnormalities leading to hormonal imbalance and polycystic ovarian syndrome. All the conditions leading to blind ending vaginal pouch like case of imperforate hymen, low transverse vaginal septum, factors leading to congenital absence of the vagina and enzyme deficiency like androgen insensitivity and $17 \alpha$-hydroxylase deficiency can be included in the differential diagnosis. The initial step taken for investigating the cause of primary amenorrhea a proper physical examination and thorough history should be taken [12]. One should look for vagina and uterus including hormonal assessment. In order to differentiate the Turner syndrome (45, XO) from Mayer-Rokitansky-Küster-Hauser Syndrome and also testicular feminization karyotype analysis should be done. If we are suspecting virilization or hirsutism then levels of total and free testosterone, DHEA sulfate should be checked. Progesterone challenge test should be done to check the function of uterus if present and levels of estradiol should be checked if there are no signs of thelarche. First imaging modality for assessing the abnormalities related to Mullerian ducts is transvaginal ultrasound. If any abnormality is seen on ultrasound, magnetic resonance imaging of pelvis including abdomen should be advised. If proper diagnosis could not be made with imaging, last resort is direct visualization of structures on laparoscopy where one can assess the severity of Mayer-Rokitansky-Küster-Hauser Syndrome anomalies [4]. 
Young females with this rare syndrome have normal body hair distribution, height and secondary sexual character. These patients have normal external genitalia but usually do not have normal full-length vagina, cervix may or may not be present. Females with this syndrome have high incidence of congenital malformations and so a careful examination of urinary tract and skeletal is done.

\section{Conclusions}

In case of primary health care setting, the evaluation of primary amenorrhea requires thorough history taking and physical examinations. In patients diagnosed with Mayer-Rokitansky-Küster-Hauser syndrome, ultrasonography and magnetic resonance imaging is necessary to decide whether surgical or non-surgical intervention should be done for treatment and proper counseling of the patient should be done to provide psychological and social support (healthy sexual practices, emotional stability and fertility). MR imaging delineates the surrounding anatomical structure better than ultrasound which is operator dependent and hence, is a better modality for investigation. Progressive vaginal dilation procedure should be attempted prior to any surgical approaches in order to produces a functional vagina. An early diagnosis and adequate management help these patients greatly.

\section{Abbreviations}

MRI: Magnetic resonance imaging; DHEA S: Dehydroepiandosterone sulphate.

\section{Acknowledgements}

Not applicable.

\section{Authors' contributions}

RKS: Designing, Concept and Major contribution in manuscript preparation. PAP: Designing, Concept, Manuscript corrections, editing and reviewing. GVM: Analysed and interpreted the patient data. RPD: Designing and Concept. SVP: Designing and Concept. HKB: Designing and Concept. All authors have read and approved the manuscript.

\section{Funding}

None.

\section{Availability of data and materials}

The data is collection from the hospital system with the permission of the competent authority. The identity of the patient is not compromised at any place.

\section{Declarations}

Ethics approval and consent to participate

Not applicable. Written informed consent was taken from the patient's parents/guardian prior to their inclusion in this study. The patient's parents/ guardian has been informed that at no place the identity of the patient will be compromised.

\section{Consent for publication}

Informed consent was taken from participant(s) parents/guardians prior to their inclusion in this study. The parents/guardians understand that their names and initials will not be published and due efforts will be made to conceal their identity, but anonymity cannot be guaranteed.

\section{Competing interests}

The authors declare that they have no competing interests.

Received: 30 September 2021 Accepted: 16 January 2022

Published online: 24 January 2022

\section{References}

1. Gutsche RM, Chagas LA, Leal R, Cunha AL, Djahjah MC (2011) Síndrome de Mayer-Rokitansky-Kuster-Hauser: relato de caso e revisão da literatura. Radiol Bras 44(3):192-194

2. Rall K, Barresi G, Walter M, Poths S, Haebig K, Schaeferhoff K, Schoenfisch B, Riess O, Wallwiener D, Bonin M, Brucker S (2011) A combination of transcriptome and methylation analyses reveals embryologically-relevant candidate genes in MRKH patients. Orphanet J Rare Dis 6(1):1-2

3. Al Dandan O, Hassan A, Alsaihati A, Aljawad L, Almejhim F (2019) A rare form of Mayer-Rokitansky-Küster-Hauser syndrome: case report and review of literature. Case Rep Women's Health 24:e00137

4. Pizzo A, Laganà AS, Sturlese E, Retto G, Retto A, De Dominici R, Puzzolo D (2013) Mayer-Rokitansky-Kuster-Hauser syndrome: embryology, genetics and clinical and surgical treatment. Int Sch Res Not 2013:1-10

5. Sultan C, Biason-Lauber A, Philibert P (2009) Mayer-Rokitansky-KusterHauser syndrome: recent clinical and genetic findings. Gynecol Endocrinol 25(1):8-11

6. Parikh RM, Nakum K, Kadikar GK, Gokhle AV (2013) Mullerian anomalies: a cause of primary amenorrhea. Int J Reprod Contracept Obstet Gynecol 2(3):3-7

7. Okhionkpamwonyi O. Complete agenesis of the Mullerian duct in a black African: diagnostic challenge: a case report and review of literature.

8. Guerrier D, Mouchel T, Pasquier L, Pellerin I (2006) The Mayer-Rokitansky-Küster-Hauser syndrome (congenital absence of uterus and vagina)phenotypic manifestations and genetic approaches. J Negat Results Biomed 5(1):1

9. Mueller GC, Hussain HK, Smith YR, Quint EH, Carlos RC, Johnson TD, DeLancey JO (2007) Mullerian duct anomalies: comparison of MRI diagnosis and clinical diagnosis. Am J Roentgenol 189(6):1294-1302

10. Yakasai IA, Daneji SM, Natasha A, Yunus EM (2015) Late presentation of Mayer-Rokitansky-Kuster-Hauser syndrome in the tropics-Northern Nigeria. J Adv Med Med Res 5:1077-1082

11. Bjorsum-Meyer T, Herlin M, Qvist N, Petersen MB (2016) Vertebral defect, anal atresia, cardiac defect, tracheoesophageal fistula/esophageal atresia, renal defect, and limb defect association with Mayer-Rokitansky-KüsterHauser syndrome in co-occurrence: two case reports and a review of the literature. J Med Case Rep 10(1):1

12. Klein DA, Poth MA (2013) Amenorrhea: an approach to diagnosis and management. Am Fam Phys 87(11):781-788

\section{Publisher's Note}

Springer Nature remains neutral with regard to jurisdictional claims in published maps and institutional affiliations.

\section{Submit your manuscript to a SpringerOpen ${ }^{\mathcal{O}}$ journal and benefit from:}

- Convenient online submission

- Rigorous peer review

- Open access: articles freely available online

- High visibility within the field

- Retaining the copyright to your article

Submit your next manuscript at $>$ springeropen.com 